\title{
The Analysis of Marine Electrical Equipment Common Faults
}

\author{
Yuan Renmin \\ Maritime College, Shandong Jiaotong University, Weihai 264200, Shandong, China \\ e-mail: yrm0019@163.com
}

Key words: Ship electrical;Insulation fault;ACB fault;Generator fault;

\begin{abstract}
This paper introduces the analysis excluded several methods commonly used electrical fault, through the analysis of several cases of typical marine electrical equipment fault, providing some reference for marine electrical management personnel in the analysis and elimination of ship electrical fault.
\end{abstract}

\section{Introduction}

With the continuous development of marine electrical, automation, ship constantly updated technology and equipment, electrical equipment becomes more and more complicated. Types of electrical faults are numerous, and often unpredictable. In case of equipment failure, as managers to calm, to have their own ideas. Commonly used analysis and the method to eliminate the electrical failure with fault diagnosis method, fault tree analysis, expert system diagnosis method, electronic equipment fault analysis.

In the use of the experiences of diagnosis method to find fault, should first understand the fault phenomenon, check the manual, through the analysis of the electrical circuit diagram to analyze fault reason, to determine the scope of possible failure, measurement or dismantling components, determine the fault point, finally repair troubleshooting and debugging equipment to normal. Following the presentation of a few cases of marine electrical equipment fault and its treatment process, the hope can reflect some principles of failure analysis.

\section{Marine electrical insulation fault}

1.1 Low insulation fault of central air-conditioning fan motor line

In 2013 June, in the process of the port, the main switchboard display power grid insulation low alarm. In the process of port, deck anchor winch equipment need the power, and the insulation low alarm occurs just at this time, so find out the idea was brought to the motor and the line of the deck machinery. However, finished with the engine, inspection confirmed that the deck machinery insulation is normal. Then you must re on possible power off equipment to check insulation low, the results were found to be the air conditioning fan motor insulation low.

The air conditioning fan support aging, fan during operation especially the No.1 fan vibration and vibration more powerful. Found in the inspection process to stop No.1 fan, electrical network insulation will soon return to normal, start the No.1 fan will appear the grid insulation low alarm. Temporary decided to No.1 fan motor fault line, after the power off with the mega-ohm meter was measured, the results of No.1 fan line are normal. Then the following experiments of two fans, first start the No.1 fan to observe a period of time there is no problem, and then start the No.2 fan, then insulation low alarm is occur, stop the No.2 fan, insulation alarm disappear. Two fans all stop, first start the No. 2 fan to observe a period of time there is no problem, and then start the No.1 fan, then insulation low alarm is occur, stop the No.1 fan, insulated low alarm disappear. The results show that a single fan operation is no problem, as long as the two fans together there will be insulated low alarm. After the power is off, the mega-ohm meter measuring No.2 fan line is no problem.

As electrical engineer at this time only with the eye view, touch the method to each section of line investigation of two motors, the results found that the power supply cable of No.2 fan motor is worn in the fan bracket around the corner, but not in direct contact with the bracket. Then the failure reason is very clear, is the vibration caused by No.1 fan motor running caused by wear and 
grounding cable insulation.When stopping the No.1 fan and then cable separated with support, grid insulating back to normal. The No.2 fan motor cable insulation low is caused by the No.1 air fan vibration. In the search for this kind of electrical fault dependence on electrical measuring instrument is very strong, often overlooked method, touch, listen to see, smell, check use facial features.

1.2 The fault of electronic governor caused by insulation damage

A ship the governor actuator appears locked occasionally in the current position, the electronic governor for the wheel is the DGS8800e type, the system principle block diagram as shown in fig.1. The electronic governor in the work process if the rotational speed signal loss or error occurs actuator locked in the current position. DGS8800e electronic speed governor speed detecting part is composed of two groups of pulse pick-up speed detection unit which is installed on the front end of the flywheel, a group of run another group of backup. In the process of working if a group of fault system will automatically switch to another group of work, in order to ensure the normal operation of the main engine. Duty engineer found in the case of actuator locking fault and not action and alarm detection system switching speed appeared. So can eliminate the faults of speed sensor, speed sensor machine intermediate junction box and DGS8800 panel serial port connection of control room subsequent examination found no abnormalities. Because it is a sporadic fault unable to carry on the investigation, can only further observation in navigational watch process.

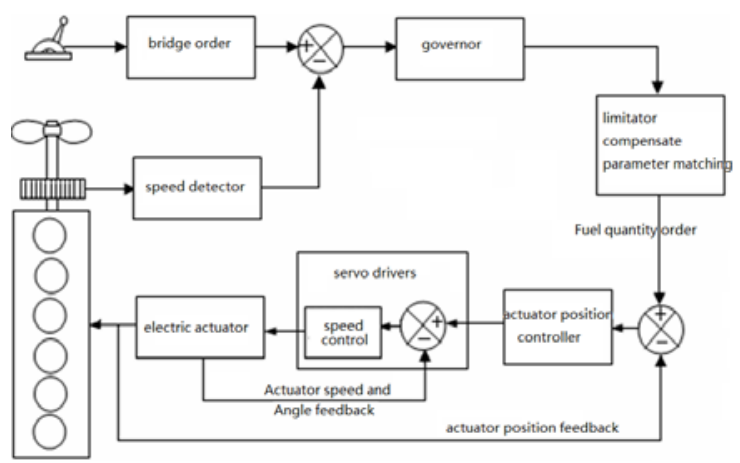

Fig.1 DGS8800e digital speed control system principle block diagram

Do daily cleaning and maintenance of the main engine at a port in the main cabin found platform next to the cable bracket is provided with a cable insulation layer of serious wear and tear. The electric engineer to check to confirm that the cable is the main engine speed signal cable, basically can be identified governor actuator lock fault is thus insulation damage caused by the rotational speed signal interference and overrun, make the system that the rotational speed signal error which issued the lock actuator commands. The cable insulation has repaired, sailing in the process does not occur actuator locking phenomenon, explain the cause of the malfunction judgment is correct.

\section{The automatic air circuit breaker fault of generator}

The automatic air circuit breaker is used in generator being called the main switch. It abbreviate ACB. The No.2 generator ACB on a ship without warning repeatedly tripping, resulting in the whole ship loss of power, the main switching panel display abnormal trip alarm. After reset, the reclosing can run normally. But this has seriously affected the safe operation of the ship. Factors leading to the ACB tripping are overload, reverse power, external short circuit, loss or lower voltage and false tripping etc. Installation fault detecting instrument in the main switch panel, the voltage and the protection switch signal access, real-time monitoring and fault locking. Run a voyage, fault detecting instrument display second alarm, namely the ACB over-current protection action. According to the parameters of the running state of power plant did not happen the flow phenomena, determine the over-current protection trip should be false action. The following key check the ACB electronic release current detection and over-current triggering part, part of the circuit for the electronic release as shown in fig.2. Three phase current of the generator through a current mutual inductor test, the $\mathrm{D}_{1}-\mathrm{D}_{12}$ diode rectifier, followed by $\mathrm{C}_{1}, \mathrm{C}_{2}, \mathrm{R}_{1}$ filter, through three groups of 
parallel divider will change the current signal generator with proportional to the DC voltage signal. For an instant super short circuit protection signal detection via $R_{2}, R_{26 / 1}, R_{26 / 2}, R_{3}$ partial voltage; second via the $R_{4}, R_{27 / 1}, R_{27 / 2}, R_{5}$ partial voltage of short-circuit short delay protection signal detection; third via the $\mathrm{R}_{28 / 1}, \mathrm{R}_{28 / 2}, \mathrm{R}_{6}$ partial voltage of overload long-time delay signal detection. Each detection signal by a diode connected to the output consists of a single junction transistor and thyristor control circuit, when to trigger action value output circuit to control the loss of voltage coil power loss so as to realize the protection action. The inspection found the over-current triggering part divider resistor R28/1 breakdown cause over-current triggering voltage higher than normal, thereby causing the switch with part load after overload trip. Replacement of the resistance, and run a few post voyage without malfunction trip phenomena, troubleshooting.

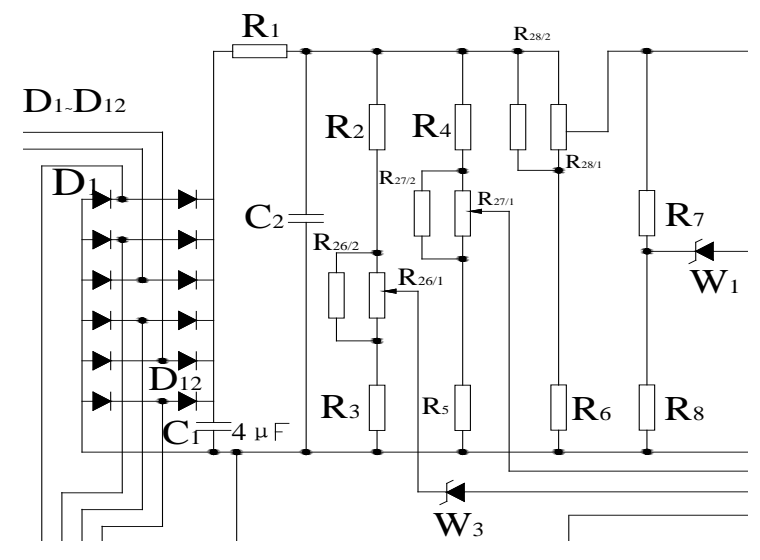

Fig.2 Electronic trip part line

\section{Ship generator fault}

3.1 Generator building voltage fault

After the No.3 generator starting, non voltage output. The generator to rotate after cannot establish normal voltage are generally due to faults in the excitation system. At first measure the excitation voltage, the voltage of excitation coil F1 and F2 is zero. Stop and check the generator's excitation system, automatic voltage regulating device and the phase compound excitation system, they are normal. Then, measure the excitation coil resistance, it is $0.8 \mathrm{ohm}$, remove the exciting coil wiring, then measuring the excitation coil resistor is $12 \mathrm{ohm}$, it is normal. Excitation coil is parallel with rectifier unit . Check the rectification output, found two rectifier diodes in S phase was the breakdown, causing a short circuit, rectifier parts without output, so it cannot be established voltage of the No.3 generator . Renew diode, start the No.3 generator, voltage is normal, and power, load operation were normal, troubleshooting.

3.2 Generator display instrument fault

Current meter of the No.2 generator every 10 minutes suddenly from normal value reached full range, and power meter from the normal value reaches the maximum inverse power, about a few minutes later, the current meter and power meter slowly return to normal, this phenomenon has been repeated, no alarm and trip phenomenon appeared in this process.

First observe the generator voltage and frequency display is normal, so it should not generator failure, should be current meter and power meter display is abnormal. Measurement of No.2 generator current transformer, found no abnormalities, so transformer no problem, doubt the power meter, ammeter or switch damaged. Because the power meter and ammeter are failure at the same time, look up and check all the wiring if the power meter and ammeter, found that the transformer current input to the power meter, and then by the power meter into the current meter, doubt power meter damaged. The power meter is removed, disintegration after the discovery, line $3 \#$ is bare wire, contact and other wire. Tape wrap, refitted and test. After a period of running, running state has been normal, fault elimination. 


\section{Conclusion}

At present, the ship constantly updated technology and equipment, marine electrical equipment fault is various, electrical engineer to continue to handle the operation principle of the new equipment, and constantly sum up, and constantly improve the maintenance and management rules in the work, to enhance the scientificity, reduce blindness. In the event of failure of electrical equipment should have a cool head, method of thinking, scientific and rational analysis to solve the problem. In the implementation process, through current flow method, cutout method, substitution method and comparative method can be combined with flexible application specific fault.

\section{Reference}

[1] Ruan Rengzhong 1. Marine electrical equipment repair guide [M]. Beijing: China Communications Press, 2000.

[2] Jiang Jinfan. The ship power station and automation [M]. Dalian: Dalian Maritime University press, 2004.

[3] $\mathrm{Xu}$ Minghua. Analysis of [J]. navigation technology a few marine electrical common fault, 2013 (1): 51-53.

[4] Jiang Wenqiang, Zhu Mingjing. Development of marine electrical automation and equipment troubleshooting [J]. communication of science and technology, 2011,(8): 89-90.

[5]Xu Shang ling. “Marine Engine Automation” . Dalian maritime affairs university press. China. 2001: p.291-299.

[6]Liu Xingqiao, Shi Zhenwei, Yao Yanchun. Control system of loading manipulator. Proceedings of the Eighth International Conference on Electrical Machines Systems, 2005:1507-1512. 